\title{
JANELAS DE EXPERIÊNCIAS: ENTRE OBRAS E LAGARTOS
} WINDOWS OF EXPERIENCE: BETWEEN WORKS AND LIZARDS

Angeli Rose do Nascimento (UNIRIO/CEDERJ; PPGE-UFRJ)

Recebido em 03 set 2017. Angeli Rose do Nascimento é pós-doutoranda em Aprovado em 29 out 2017.

Educação na UFRJ; Doutora em Letras pela PUC-Rio, Estudos de Literatura (2007); Mestra em Educação pela PUC-Rio (2001); Especialista em Literatura Brasileira pela UERJ (1986); Esp. em Jornalismo Cultural pela UERJ(2017); atualmente atua como professora-tutora em EAD no curso de Pedagogia da UNIRIO/CEDERJ, além de orientar trabalhos de conclusão de curso; é avaliadora de diversos periódicos acadêmicos como EAD em FOCO; Revista Brasileira de Pesquisa (Auto)biográfica, entre outros; mantém um Memorial dialógicx em página de FACEBOOK, sob alcunha de Capitu Nascimento; já foi blogueira; foi docente substituta em universidades públicas e privadas das disciplinas Literatura Brasileira (UFRJ), Teoria da Literatura História da Literatura (UEMA); e Avaliação no Contexto escolar (ISAT); foi professora de Educação Básica por mais de 20 anos (CEAT-RJ; CAP-UERJ). Suas pesquisas se concentram na área de Literatura e Ensino, com especial atenção para a formação de leitores e mitologia literária. Recentemente recebeu o prêmio social Excelência e Qualidade na categoria Educação, com a certificação do título de Comendadora pela BRASLÍDER (2017, SP), que somou ao prêmio para o projeto de tese, 2003, pela FUNDACIÓN MARÍA ZAMBRANO (ES) e ao da ABL, 2004, por texto publicado 
em antologia do mesmo ano. E no momento desenvolve projeto de pesquisa sobre Literatura digital e a formação de professores-leitores em formação inicial, além de colaborar com os grupos de pesquisa GEPEAD/ UNIRIO, sobre aprendizagem e NEPAA/UNIRIO, sobre performance e práticas culturais. E é secretária adjunta da ADOPEAD-RJ/Ssind-ANDES para o biênio 2017-2019. CV_Lattes: http://lattes.cnpq.br/4872899612204008 E-mail:23capitu33@gmail.com

Resumo: Este artigo apresenta um exercício de leitura crítica do conto $O$ Lagarto, de José Saramago, com ilustrações de J.Borges, tendo como operador o conceito de experiência em Larrosa (1996), num viés dialógico (Bakhtin, 2003) em que a narrativa infanto-juvenil é apresentada tanto na perspectiva histórica como atual. As categorias de experiência de leitura e leitura como experiência norteiam os encaminhamentos dados à leitura significativa do conto literário, articulado à narrativa visual e plástica do artista Borges. Justificase tal exercício através de breve relato de experiência com a circulação do literário em espaços e grupos sociais diversos que em práticas de leitura também diversas deram a ver a potência desta narrativa e da contação de histórias, se antecipando a esta produção sistematizada. Para tanto, lançou-se mão de aspectos referentes à estruturação de narrativas (Todorov, 1970) e à caracterização da produção literária contemporânea portuguesa (Ramos, 2016) em que o premiado autor português se insere reafirmando alguns traços estilísticos e culturais. Em seguida, explora-se o conceito de "maravilhoso" tensionado com o conceito de "fantástico", de maneira a sugerir uma aproximação temática, no conto de referência, entre poesia e extraordinário. Ao final, considera-se que o texto saramaguiano reafirma a noção de "polifonia", tanto na constituição da subjetividade leitora como na de autoria. Palavras-chave: Experiência; Dialogismo; Polifonia; Fantástico; Maravilhoso; Infanto-juvenil. 
Abstract: This article is an exercise in critical reading of José Saramago's short story The Lizard, illustrated by J. Borges, through the concept of experience in Larrosa (1996), in a dialogical interpretation (Bakhtin, 2003) which analyzes this children's narrative both in historical and present perspectives. The categories of reading experiences and reading as experience guide the analysis of this oeuvre. This exercise is justified by a brief account of an experience of literary circulation in various spaces and social groups in which diversified reading practices showed the power of this narrative and of storytelling. To this end, elements referring to the structuring of narratives (Todorov, 1970) are employed, as well as the characterization of Portuguese contemporaneous literary scene (Ramos, 2016) of which the prizewinning Portuguese author is part of, reasserting some stylistic and cultural characteristics. Afterwards, the concept of "marvelous" is explored together with the concept of "fantastical", in a manner to suggest a thematic approach in this short story between poetry and extraordinariness. In the end, the Saramaguian text is concluded to be a reaffirmation of the notion of "poliphony", both in the making of reading subjectivity and in authorship.

Keywords: Experience; Dialogism; Poliphony; Fantastic; Marvelous; Children's story.

\section{INTRODUÇÃO}

Sobre janelas podemos começar a dizer que são aberturas, que deixam ver e ser visto. Dintéis. (Gosto desta palavra, acho-a gorda de sentidos. Adiposa até.).

Mas estamos em tempos de janelas sobre janelas; de janelas múltiplas e concomitantes, numa tecnológica simultaneidade infinita. Incontinentes na tela a nossa frente. E não é bem dessas 
que desejo falar, talvez me aproxime delas, porém, prefiro determe nas janelas que a leitura literária pode abrir. Menos imediatas e contemplativas. E uma delas é a da experiência. Experiência como algo "intransferível", "intransitivo" e irrepetível, alerta Larrosa (2016). Assim começou este exercício de leitura agora escrito ${ }^{1}$, antecipado por vivências em outros espaços institucionais de formação, como no grupo de estudos e pesquisa em que desenvolvo investigação sobre experiências de leitura literária digital.

A experiência para o filósofo espanhol é um "acontecimento" e como tal se afasta das noções de fato, conceito, objeto, ou produto, porque ela "é o que nos passa, o que nos acontece, o que nos toca. Não o que se passa não o que acontece, ou o que toca" (2016, p.168). Todavia, é importante e necessário mesmo distinguir experiência de informação, o que também vai levar à compreensão de que ela, "a experiência tem a ver com o não saber, com o limite do que sabemos" (p.69).

A partir disso, associo janela, experiência, leitura e literatura para compreender que a leitura como experiência, a leitura literária, é o que nos acontece - retomo (LARROSA, 1996, p.32). E sobre tal acontecimento, quando nos acontece, é que irei desenvolver uma breve reflexão no exercício de leitura de O Lagarto, de José Saramago. Além desse exercício, apresentarei notícias sobre a literatura infantil e juvenil portuguesa atual, buscando posteriormente inserir o texto literário de referência no contexto delineado, depois de apresentar o conto de Saramago e J.Borges, objeto também de reflexão 1 Tal iniciativa, antecipada por avaliação em forma de parecer deste livro incluído no PNBE/2016, posteriormente se tornou objeto de prática pedagógica proposta em aula de especialização, presencial, para professores da educação básica, narrada em breve relato de experiência e, por fim, desdobrou-se em reflexões sistematizadas sobre o conto neste artigo. 
na tensão entre o "maravilhoso" e o "fantástico"; por fim, trarei algumas considerações finais, inconclusivas, em torno de todo o processo de elaboração deste exercício de leitura crítica.

\section{BREVE RELATO PARA CIRCULAÇÃO DO TEXTO LITERÁRIO}

No grupo de pesquisa ${ }^{2}$ em que atuo regularmente temos a prática de estudos teóricos e de leituras compartilhadas de textos literários. Na ocasião da avaliação dos livros inscritos para o PNBE 2016, entre outros, o volume O Lagarto de José Saramago e J.Borges ficara sob minha responsabilidade. A leitura, os comentários e o parecer técnico deveriam ser elaborados para socialização posterior e submissão à votação do grupo, com o fim de indicar os livros ao prêmio na categoria de análise. Naquele momento, meu voto no grupo para ser encaminhado fora no livro de Saramago e J.Borges, o que mais adiante se confirmou na FNLIJ.

Além disso, como professora convidada para ministrar um dos módulos da especialização do CEPESB $^{3}$ em Literatura Infantil e juvenil para professores de Educação Básica, no caso, sobre "A literatura infantil e o contemporâneo", propus a prática de leitura e análise de vários livros de literatura brasileira infanto-juvenil, quase todos recém-lançados, por pequenos grupos de discussão formados espontaneamente pelas alunas. O livro $O$ Lagarto estava entre aqueles. Recordo que o grupo destacou alguns elementos constituintes da narrativa que de fato conferiam singularidade ao

2 Linha de pesquisa Currículo, Docência e Linguagem da PPGE/UFRJ, que acolhe a pesquisa institucional do grupo coordenado pela Prof. Dra. Patrícia Corsino no LEDUC, sob a rubrica de Infância, Linguagem e escola. Nesta atividade desenvolvo investigação de pós-doutoramento, sob supervisão da mesma docente-formadora.

3 O curso de especialização, noturno e presencial, realizou-se até o 1ㅇ. semestre /2017, na Faculdade de educação da UFRJ, sob a coordenação da Prof.Dra.Patrícia Corsino. 
texto e consequente envolvimento com a leitura da narrativa, tais como: a edição caprichada (capa dura); as ilustrações de J. Borges com reproduções de xilogravuras de predominância de tons terrosos em contraste com o preto e branco; a temática do fantástico, porém ambientada em ambiente urbano e atual; a articulação entre texto e gravuras com a sensível dramatização de cenas narradas; algumas expressões idiomáticas que marcavam as diferenças entre o Português falado em Portugal e no Brasil; a presença de um poema no meio da narrativa em prosa; e o fato de saber tratar-se de um texto de J. Saramago, predispondo o leitor a reconhecer qualidade na obra em questão; e a adequação do texto para ser lido por crianças do ensino fundamental, principalmente. Enfim, atentas e bem exigentes, aquelas professoras-leitoras deram a ver a consistência da narrativa literária de Saramago e ao mesmo tempo o prazer de ler uma boa história contada à moda dos grandes "contadores de causos", em que o inesperado, o inverossímil são fortes temperos para a imaginação, num ato de ludicidade e invenção.

A sistematização, em boa medida, de toda aquela profusão de ideias e percepções disparadas pela prática de leitura compartilhada também acerca dos textos literários propostos, $O$ Lagarto era um deles, foi estruturada na etapa seguinte do encontro, com a exposição de alguns índices que se tem tomado como regulares e constantes nas narrativas infantis e juvenis, em certo contraste com o que se vinha classificando como narrativas do maravilhoso, contos de fadas etc, gêneros consagrados e de grande importância no repertório docente da educação básica, principalmente, das séries iniciais do Ensino Fundamental. Algumas considerações retomo mais adiante, a título de situar tanto a produção contemporânea para a 
infância como para introduzir a questão do fantástico presente no conto de Saramago e que tem algo a nos dizer sobre o contexto contemporâneo, também produtor de narrativas que reelaboram tal elemento, sob perspectivas instigantes para um tempo como o que vivemos.

Por tudo isso, a circulação do texto de $O$ Lagarto em momentos tão diversos, assim como em companhias tão afeitas à leitura literária por algumas mesmas razões e por outras tantas diferentes, levou-me a conviver com o volume um tempo maior do que o esperado inicialmente e com isso a procurar incorporá-lo de vez nas minhas tarefas acadêmico-profissionais. O acaso, nesse caso, me protegeu de fato e manteve o desejo de seguir um pouco mais adiante com a leitura do conto, resultando neste breve exercício de leitura, no qual o "fantástico" é o foco disparador da análise do texto literário em questão. Mas "é incapaz de experiência aquele a quem nada lhe passa, a quem nada lhe acontece, a quem nada lhe sucede a quem nada o toca, nada Ihe chega, nada o afeta, a quem nada o ameaça, a quem nada ocorre" (LARROSA, 2002, p.6). Então, vamos a mais uma janela aberta para o "saber da experiência".

\section{TENDÊNCIAS CONTEMPORÂNEAS DO OUTRO LADO DO ATLÂNTICO}

Ramos (2016) apresenta-nos de forma bem objetiva e didática o panorama que acolhe as "tendências contemporâneas da literatura portuguesa para a infância e a juventude" e alguns dos desafios atuais dessa produção comentada. Segundo a autora, na última década deste século houve significativas mudanças no contexto da leitura literária, que seria uma consequência de vários fatores conjugados. 
Neste breve levantamento, cabe destacar a "consciência social sobre os benefícios da leitura e da sua promoção desde a tenra idade." (RAMOS, 2016, p.32). Aliado a isso, há a constatação estatística do crescimento do número de publicações para crianças, as políticas públicas em Portugal em prol da leitura, como por exemplo o PNL, programas de Língua Portuguesa do Ensino Básico, as novas metas curriculares do Português do Ensino Básico e certa evolução do universo editorial e o preço acessível do livro.

Em realidade, o objetivo principal do "plano" desde 2007 é "elevar os níveis de literacia dos portugueses", o que reconheceu a qualidade gráfica das últimas produções, além da aposta no aumento do número de bibliotecas escolares e públicas. Entretanto, no que tange às obras selecionadas para listas oficiais, as políticas públicas envolviam os chamados textos clássicos, algumas obras contemporâneas, outras universais, autores portugueses, lusófonos, estrangeiros, além de reescrituras da literatura tradicional de transmissão oral, segundo os critérios estabelecidos. Tem-se, então, um "plano de leitura" que contempla distintas variantes da língua portuguesa, europeia, brasileira e africana; cosmovisões diversas, enfim, o múltiplo, o diverso e o plural como categorias fundamentais para a constituição de acervos.

\section{EDIÇÕES CONTEMPORÂNEAS PORTUGUESAS PARA A INFÂNCIA E A JUVENTUDE}

A legitimação das obras nos últimos anos tem passado por estímulos como prêmios, seleções oficiais escolares, tanto para os textos literários como para as ilustrações desse gênero. A isso se soma, o crescente interesse no meio acadêmico nacional e 
internacional por desenvolver investigações e teses, além de eventos sobre esta produção para a infância e a juventude. E, curiosamente, o mercado português direcionado para crianças e jovens tem sido resistente à crise econômica e social no mundo globalizado.

E a partir dessas considerações iniciais, Ramos caracteriza a "edição para a infância e a juventude em Portugal":

1. Consolidação de autores que vinham publicando desde os anos 70-80;

2. Surgimento de novos autores através de prêmios e seleções oficiais;

3. Novos autores oriundos de outros meios, como jornalistas e profissionais do ensino;

4. Colaboração pontual de autores renomados que não escrevem para esse mercado regularmente;

5. Publicações de traduções de obras relevantes, clássicas e contemporâneas;

6. Desenvolvimento crescente da componente ilustrativa;

7. Aumento do número considerável de ilustradores e criadores;

8. Surgimento de novas e muitas editoras especializadas;

Contudo, é interessante ter a informação de que a escrita literária portuguesa nesse gênero, segundo a autora de referência, não teria apresentado "alterações" significativas, mesmo dando atenção "a temas e/ou universos relevantes (RAMOS, 2016, p.36).

Ao mesmo tempo, "a situação periférica desta literatura em relação à literatura canônica", isto é, ao sistema literário canônico, talvez explique em parte "a abertura e a permeabilidade" (RAMOS, 2016) 
a questões como ecologia, temas ambientais, o multiculturalismo e a interculturalidade, racismo, xenofobia, sexualidade, guerra, violência, política e episódios históricos mais controversos.

Assim, o que se identifica ainda é que o ponto de vista infantil é estruturador de tais textos contemporâneos, sem abrir mão de questionamentos e reflexões, e nas reescrituras de certa tradição oral, aparece a "revisão do maravilhoso", a "exploração da imaginação", "do fantástico" e do "nonsense". Já no ponto de vista linguístico, os textos mais inventivos e criativos, às vezes até considerados subversivos, transgressores, apresentam intenções simultaneamente intenções lúdicas e didáticas da língua que também é alvo de experimentações, de jogos de palavras e de ritmos, ou de humor, ou cômico e até como anteriormente indicado do nonsense (RAMOS, 2016, p.57).

\section{O ÁLBUM ILUSTRADO}

Esse gênero tem reafirmado com sucesso e qualidade a articulação entre texto e imagem, por vezes, de um único autor ou de parceria entre escritor e ilustrador. Ao se difundir por elementos paratextuais como formato, número reduzido de páginas, policromia e articulação sinérgica entre texto e imagem em forma híbrida de narrar, resultando em uma fruição precoce e autônoma para os pequenos leitores.

\section{OS TEXTOS POÉTICOS CONSOLIDADOS}

O aparecimento de uma poesia portuguesa para a infância mais lúdica, intensificadora da dimensão plástica da palavra, certa intenção filosófica assumida, primando pela originalidade e a qualidade literária e poética. 


\section{DESAFIOS}

Algumas dificuldades são comuns ao mercado editorial brasileiro, como a sobrevivência de pequenas editoras ante os grandes grupos editoriais, assim como a produção acadêmica ainda reduzida sobre a literatura para a infância e a promoção de autores portugueses nesse campo serem pouco divulgados. Por outro lado, a convivência da diversidade através do segmento de muitos autores é um desafio para o pequeno leitor, mas que desde pouca idade poderá entrar em contato com realidades e mundos diversos e imaginários, desafiando as próprias vivências.

\section{ENTRE OBRAS E LAGARTOS}

O livro O Lagarto, de José Saramago, com ilustrações de J.Borges, foi publicado em 2016 pela Cia das Letrinhas aqui no Brasil em parceria com a fundação José Saramago, além de trazer na capa dura o selo de autor "Prêmio Nobel", ganho pelo escritor português em 1998. O volume catalogado como conto, apresenta dimensões generosas de caderno com papel fosco e policromia reduzida a 4 cores (tons terrosos, azul, preto e verde), lembrando que a cor preta é a marca da xilogravura no contrate entre traço e página.

O artista ilustrador, J.Borges, também é conhecido como cordelista e tem reconhecimento em toda a América Latina na condição de artista plástico e autodidata.

Quanto ao livro, vale conferir o vídeo de registro do lançamento em Portugal na Fundação José Saramago, junto a editores e a sua ex-companheira, a jornalista Pilar ${ }^{4}$.

4 Vídeo de lançamento de O Lagarto, de José Saramago, em Óbidos: https://www. youtube.com/watch? $v=Y A k-1 T d Z K X 4$ 
Já sobre este estranho protagonista da história, O Lagarto, vale conferir o vídeo dentre uma série que apresenta um lagarto "assustador", exatamente na condição inicial descrita pela pequena narrativa de Saramago e que está disponibilizado em link abaixo. Neste, há a possibilidade de realizar a visão do bicho e suas reações ante os estímulos humanos, confirmando a agressividade humana que é sugerida no conto diante da presença ameaçadora do lagarto.

Há um jogo entre real e ficcional sendo proposto ao leitor deste exercício, quem sabe, provocando uma experiência a ser mais bem elaborada na leitura dos comentários sobre o "conto de fadas" contado na letra de Saramago 5 .

"A história é de fadas". O enredo é simples (e não é). É um "conto de fadas", e embora elas não apareçam, sabe-se de suas intervenções através do narrador. Trata da aparição inesperada de um lagarto gigante no meio da rua de uma pequena localidade de nome Chiado. Tal aparição gera uma quebra, uma ruptura brusca, na rotina daqueles moradores e passantes, a ponto de o animal ser visto como uma ameaça incontornável e inexplicável por todos. O bicho que fica praticamente imóvel todo o tempo é cercado por olhares aterrorizados, que promovem o planejamento de uma ação de ataque contra ele, o lagarto. "E a salvo das janelas, pessoas davam conselhos e opiniões. Mas tudo contra o lagarto." Porém, no momento em que esta ação está a se efetivar há outro surpreendente acontecimento, relacionado ao sobrenatural, que tira da cena discursiva a população local, e a partir daí o leitor só tem notícias do lagarto que agora está transformado e novamente

5 Vídeo documental amador, O lagarto assustador no YOUTUBE: https://www.youtube. com/watch?v=TJUxbgtEJ7o 
se transforma, assumindo a forma final de uma pomba que voa para o céu. A história é essa, porém, o modo como é contada e a linguagem tanto poética como pictórica surpreendem também o leitor, mesmo com o texto curto apresentado.

\section{ENTRE O MARAVILHOSO E O FANTÁSTICO LAGARTO}

O narrador de $O$ Lagarto, como todo bom contador de histórias, empreende um ritmo ágil, com frases curtas e dialógico à história apresentada. E logo no início ele, o narrador, situa o leitor em relação ao gênero literário e à legitimidade dos contos de fadas hoje em dia, que ele diz ser a história a ser contada como algo do passado e hoje pouco acreditada.

No entanto, esse aparente contrassenso da contação, de uma história esvaziada por ser de "fadas", é o que estrutura logo de início o pacto ficcional entre leitor e narrador. Ao usar expressões ao modo português e de certa sabedoria popular, para o leitor brasileiro, Saramago na voz do narrador amplia de imediato os referenciais culturais e linguísticos do leitor brasileiro. A saber: "(...) mas isto de fadas foi chão que deu uvas"; "pois vá o barco à água, que o remo logo se arranjará". No entanto, é também a ironia o elemento que norteia a iniciativa de narrar o que há muito o narrador diz querer fazer, contar uma história de fadas, além de provocar no leitor uma desconfiança sobre o que de fato esse narrador pretende ao contar uma história desacreditada. Com isso, Saramago explora como recurso a metalinguagem, que colabora para a densidade da linguagem utilizada.

Neste sentido, o narrador irônico reafirma a tradição ao mesmo tempo em que reconhece que as mudanças ocorreram a ponto de 
transformarem as relações entre leitor/ouvinte e as histórias de fadas, isto é, as histórias que trazem o "maravilhoso" como marca estruturadora do mundo imaginário inaugurado pela literatura. $E$ conta dando a sua impressão ao término do conto: "Há por aí quem não acredite? Eu bem dizia: isto de fadas já não é nada o que era".

Entre o "maravilhoso" e o "fantástico" há o estranho que carrega o "sobrenatural" e se superpõe ao que seria natural ou naturalizado nas histórias do "maravilhoso". Tão estranho que foge a qualquer explicação aceitável ou cabível, ou lógica, este ser gigante que se transforma de lagarto em uma flor, uma rosa vermelha, que por sua vez, também se transforma em uma pomba, talvez, para desespero de uns e perplexidade de outros.

Sobre o "fantástico", o estudo de Vladimir Propp é comentado em artigo por Marcia Marçal:

O sobrenatural é tratado de uma forma muito diferente pelo discurso narrativo construído pelo gênero Fantástico. O evento sobrenatural surge em meio a um cenário familiar, cotidiano e verossímil. Tudo parece reproduzir a vida cotidiana, a normalidade das experiências conhecidas, quando algo inexplicável e extraordinário rompe a estabilidade deste mundo natural e defronta as personagens com o impasse da razão. (2009, p.19)

No entanto, o recurso de oscilar entre a razão que tenta explicar o elemento fantástico não acontece na trama instaurada por Saramago, ao contrário, a ironia do narrador é fator de distanciamento do leitor de qualquer possibilidade de identificação com a dúvida. Em realidade, o leitor poderá até identificar-se com os medos e as sensações disparadas pelo "monstro", pelo estranho, 
mas tais sentimentos não são postos em dúvida por qualquer explicação do que venha a ser aquele elemento fantástico.

Portanto, está posto o lócus imaginário na trama narrada, assim como está proposto pela ilustração que, desafiadora de limites, tal qual a narrativa, explora as diversas figuras citadinas misturadas ao gigante lagarto em cenas que dramatizam para além do contado. J.Borges suprime linhas divisórias que poderiam demarcar territórios e espaços. O ilustrador conserva apenas o chão na cor preta, tal como a sugestão de um asfalto, indicando a rua em que se planta nosso invasor, a princípio.

Assim, a desproporcionalidade na ilustração é também fator de efetivação do "maravilhoso" no conto, com certa ambiguidade, uma vez que sem ruptura faz conviver na cena pictórica o absurdo de uma perspectiva sem medidas. Ao mesmo tempo, nessa temporalidade singular que o maravilhoso instaura é dada ao leitor a temporalidade do fantástico que rompe com a cronologia compassada e marcada. Nada importa a não ser o acontecimento introduzido pela presença do invasor e que na voz do narrador é sugerido coisas de fadas, as quais afinal também o retiram pela transformação antes que seja destruído pela população local: "O qual lagarto, de repente [por intervenção das fadas, não esqueçam], se transformou numa rosa rubra, cor de sangue (...)" (SARAMAGO,2016, p.23).

A metáfora agora instaurada é a da "ferida na cidade", ou seja, a rosa é a marca deixada na passagem daquele ser estranho por aquela comunidade que o rejeitou e escolheu a violência para lidar com a ameaça. Nessa seção dramática, parece que o narrador precisa de tempo, assim como entende que o leitor deverá precisar 
de tempo para certa contemplação, pois as páginas seguintes são apenas ilustração, grandes e em 2 planos, de maneira que no chão está o lagarto e a ele acoplada a rosa e em outro plano suspenso o povo local e figuras femininas de um lado e em outro lado, um pássaro negro, como se fosse o negativo do que está por vir a ser ainda "revelado", qual fotografia ou mesmo a técnica de gravação da xilogravura.

Na retomada da narrativa, há a descrição da nova forma tomada pelo bichano suspeito e ameaçador. Operação discursiva e textual que é interrompida pela pergunta de uma personagem sobre o que teria acontecido, porém, sem resposta alguma. O conto prossegue com a narração da metamorfose vivida pelo lagarto, agora em flor e finalmente em forma pomba. Tudo "de repente" e "rapidamente" como é próprio das ações mágicas ou sobrenaturais. Ações em que o aspecto processual não aparece ou não existe.

A assimetria e as desproporções figurativas contribuem para a construção do sobrenatural que rompe com a ordem, trazendo o extraordinário, já desenhada pela "aparição", elemento constituinte do fantástico, segundo Todorov (1977). Deste modo, o ser que antes fora ameaça, compondo uma realidade disruptiva, agora é um elemento passível de pacificação entre as visões que se desesperaram naquela cidade.

Com a pomba voando para o céu azul acabou-se a história, ou, quem sabe, talvez aí tenha começado para o leitor que se pergunte o que aconteceu, ou que se passou consigo lendo aquela história de fadas que não aparecem, mas "dizem" que agem no plano invisível que só o discurso parece ser capaz de indicá-las ou anunciar suas presenças. 
Não há heróis nesse conto saramaguiano, e se o quisesse, talvez, não ficasse bem dar tal função às fadas, ao sobrenatural, ao maravilhoso, que afinal é o que salva o nosso gigante lagarto da destruição intentada pelo humano. Porém, à luz de Le Goff (1980), o que há é um "happy-end", considerando que o monstro ameaçador é metaforseado em uma flor e depois em uma pomba, sinais de uma cultura ocidental e cristã em que os símbolos finais são pacificadores, quer pelo sentimento de paz, quer pelo divino contido nos sentidos assumidos pela pomba ao longo da história cristã, pois,

As emoções de medo ou horror, bem como a sensação de nojo dos seres ameaçadores ou monstruosos glorificam uma concepção maniqueísta do mundo: o Bom, o Bem, o São e o Divino saem vencedores no conflito com o Mal. A problematização do real no fantástico assume, neste sentido, o caráter de uma luta primordial entre forças antagônicas, da qual saem vitoriosos os valores que o pensamento logocêntrico aceita como positivos. (CHIAMPI, Apud MARÇAL,2009, p.6-7)

\section{ENTRE O SER E O ESTAR}

O Lagarto de J.Saramago convida a nós, leitores de sua história de fadas, a entrar no mundo do "maravilhoso", através do sobrenatural. Porém, pode-se dizer que a narrativa está mais próxima do fantástico que tomamos tanto a ordem temporal instaurada pela interrupção, como pela espacialidade ocupada circunstancialmente pelos personagens. Cabe destacar que no conto não mais importa o que se é, mas o que se está, pois é essa 
a potência do personagem animal. Por intervenções externas, segundo o narrador, ele, o lagarto, deixa de ser animal, passa a vegetal e novamente passa a outro animal, porém de características bem diferenciadas entre si, além de também sugerir a possibilidade de nova relação com o humano. Neste sentido, é o que se está, a forma assumida, que pode determinar as relações com a realidade encontrada ou instaurada.

Ao lado disso, sabemos que a língua portuguesa apresenta a singularidade de estabelecer a diferenciação entre esses dois verbos, "ser" e "estar", e que mais diretamente falam de temporalidades diversas. Ora, o tempo é o elemento capaz de estruturar qualquer realidade agindo sobre ela tanto para fixá-la como para modificá-la no espaço. Além disso, essa distinção entre os verbos podem sugerir o "estado de poesia" que chega a ser promovido pelo narrador ao final quando introduz o gênero literário com uma quadra bem ao gosto da memória cantada popular e medieval na forma de versos heptassílabos:

Calados, muitos recordam,

Na prosa das suas casas,

O lagarto que era rosa,

Aquela rosa com asas. (SARAMAGO, 2016, p.17)

Através dessa narrativa é possível discutir a potência da linguagem que também instaura e inaugura realidades discursivas, conferindo assim a verossimilhança, própria da ficção, mas no caso de Saramago, mestre da prosa, também instalar a ruptura com o presumível e o pretendido. Ora, se a poesia é também algo fora da ordem da linguagem estabelecida com fins estritamente comunicacionais e portanto, algo de outra "ordem", singular e 
singularizante, nada melhor para "falar" do diferente, do fantástico que interrompe como a poesia, porque esta também interrompe a "ordem" das coisas com sua potência de transfiguração de realidades, ou seja, potência de metamorfosear a realidade das coisas e dos seres que a ela são submetidos.

Questões como o diferente, o estranho, assim como a mudança e a metamorfose, são categorias temáticas que podem ser exploradas na extensão desses ou de outro exercício de leitura do conto, o que na 4å. Capa o narrador anuncia em destaque: "O que será? Convido você a descobrir - e depois ter coragem de afirmar que continua não acreditando em fadas". Há janelas a abrir. Há leituras a empreender. Há experiências possíveis de se nos acontecerem.

O disjuntivo par "ser/estar" cantado por outros poetas, como o nosso baiano Caetano Veloso em Língua, reafirma a condição entre línguas, intercultural possível, exatamente pela celebração da diferença. Caetano canta: "Gosto de ser e de estar/ gosto de sentir a minha língua roçar a língua de Luís de Camões", que na poesia da canção o eu lírico admite a semelhança, mas reconhece também as diferenças e as celebra, mesmo na forma de atrito, superfície com superfície. Planos que se relacionam. No caso do conto, os planos do real e do imaginário se relacionam através da corporeidade leitora que aceita o jogo ficcional a cada página virada, porém, precipitada, quem sabe, como traços na memória do leitor.

\section{A HISTÓRIA NA JANELA DA HISTÓRIA}

A história contada de um lagarto gigante que inexplicavelmente se metamorfoseia provoca uma questão em específico, se nos dispusermos a pensar a partir de elementos extra-literários que 
compõem a biografia do autor. É sabido que Saramago fora em vida ateu e que em sua obra o ceticismo, enquanto corrente filosófica, também se materializava na ironia. E nesse conto parece não ser diferente, o autor conta histórias para a infância, mas adianta-se em provocar a dúvida acerca da existência desses entes imaginários.

Então, por que a "pomba" como forma final e não necessariamente conclusiva? O que estaria em termos de extensão de sentidos que estabelecesse alguma conexão entre vida e obra? Ou entre histórias datadas e não datadas, talvez até atemporais como o "maravilhoso" e o "fantástico" podem explorar.

Não se trata de enquadrar elementos do texto em uma forma de sentidos, porém, trata-se de um exercício de leitura que também requer a operacionalidade de algumas informações de que dispomos, enquanto leitores e cidadãos. Assim, podemos pensar sobre toda a tradição cristã que tem na "pomba" o símbolo do divino, no caso, do Espírito Santo. Mas também é símbolo da paz num outro contexto civil, embora biblicamente estivesse associada a sacrifício.

Neste sentido, há outras vozes que constituem aquele narrador, como há vozes que constituem nossas subjetividades leitoras e do escritor também. Vozes que numa razão polifônica (Bakhtin, 2003) dialogam entre si e se relacionam entre si e com as demais vozes que com elas interagem. O "dialogismo" bakhtiniano pode ser sentido aqui ao lidarmos com as histórias que engendram uma história e não a história. E nessa diversidade de realidades, mundos e vozes, podemos encontrar no texto de Saramago a ressonância da força influente de uma cultura, por sugestão cristã. E em nada isso se torna uma contradição para compreendermos quer o conto, 
quer algo a mais da biografia de Saramago, mas nos habilita e refletir que a voz cultural também ressoa no voo daquela pomba e que a subjetividade do escritor em alguma medida também nos dá a ver(-se). A potência dessa polifonia, mesmo num escritor ateu, que sabe a força dessa presença pombalina na narrativa, sugere que nos afastemos do eu absoluto para lidarmos melhor com um eu relacional, aquele eu relacional que não suportou o estranho e fantástico gigante lagarto introduzido na realidade cotidiana daquela população citadina.

A "polifonia" bakhtiniana também pode abrir janelas para as vozes que se confrontam no leitor perante o texto literário ou poético.

A pergunta da "velha", personagem feminina reativa, que do hospital indaga sobre o que teria acontecido, ante o silêncio sobre o fim do lagarto, uma vez que a destruição dele é interrompida também violentamente pela metamorfose disparada pelas "fadas", é uma pergunta sem resposta. Resposta que talvez dê lugar ao leitor silenciado pela escuta da narrativa. Mais uma janela que poderá ser aberta ao leitor atento. Mas no plano estrutural da narrativa do gênero fantástico, segundo Todorov (1977, p.53), haveria uma hesitação dos personagens entre uma explicação lógica e a imposição do sobrenatural a ponto de contagiar inequivocamente o leitor. Esta hesitação seria um elemento definidor de tal gênero. Isto caracterizaria inconfundivelmente a narrativa aproximando-a do gênero. Segundo o estruturalista: "O fantástico é a hesitação experimentada por um ser que só conhece as leis naturais, face a um acontecimento aparentemente sobrenatural" (TODOROV, 1977, p.72). Podemos sugerir que a pergunta no conto $O$ Lagarto não indica hesitação, tampouco a falta de resposta pode ser a 
conclusão exata sobre isto, entretanto, a pergunta sem resposta, sem explicação, pode provocar no leitor a hesitação necessária para - ainda que por minutos - se pergunte e busque uma explicação ou racional, lógica, ou de reafirmação do irracional, do alógico, ou simplesmente desperte para o inconcebível realizado a sua frente.

Neste sentido, temos a introdução do maravilhoso que não questiona esse sem fronteiras entre o real e o extraordinário, ao mesmo tempo em que parece ter esse quê de divino e sagrado (uma rosa que vira pomba); e a intervenção de um ser que se impõe no cotidiano, exigindo que se olhe para aquele espaço comum, o asfalto, ao mesmo tempo, que parece ser necessário afastar-se dele por um medo atávico vivido pelos cidadãos locais.

Podemos perguntar entre obras: quem tem medo de lagartos? Quem tem medo de obras literárias?

\section{CONSIDERAÇÕES FINAIS}

E o que faz a poesia? A literatura? A arte? Senão transformar realidades e tirar as palavras de suas zonas de conforto, a partir de janelas que a imaginação abre ao leitor atento e disposto ao jogo com o ficcional, ou com o estético em última instância (?).

Ora, e o que é a poesia, a literatura, a obra de arte, senão o irrepetível, o intransferível, o intransitivo, tal qual a "experiência" como vimos a partir de Larrosa (2016)?

O conto de Saramago nega a condição de mero experimento para o texto literário e, num laboratório da vida, sugerindo a experiência através da leitura, tal e qual a poesia propõe o labor da imaginação. Aquilo que nos transpassa e expõe-nos a travessias pelas palavras. Portanto, é no poético enlaçado, através 
do fantástico e do maravilhoso narrados neste conto do autor português, que janelas de experiências como leitura poderão tomar novas formas de linguagem, quer para leitores, quer para novos contadores de histórias, abrindo o pensamento para um sem fim de novas palavras-janela.

\section{REFERÊNCIAS}

BAKHTIN, Michael (2003). Estética da criação verbal. São Paulo: Martins Fontes. DEBUS, Eliane; JULIANO, Dilma Beatriz; BORTOLOTTO, Nelita (2016). Literatura Infantil e Juvenil: do literário a outras manifestações estéticas. Santa Catarina: Copiart/UNISUL.

LARROSA, Jorge (2002). Notas sobre a experiência e o saber de experiência. Revista Brasileira de Educação. Jan/Fev/Mar/Abr, (19). In http://www.scielo.br/ pdf/rbedu/n19/n19a02.pdf Acesso em 15.Mar.2017. (2016). Tremores. Minas Gerais: Autêntica, 2016.

(1996). Experiência, leitura e formação. Barcelona: Laertes editores.

MARÇAL, Marcia (2009). "A tensão entre o maravilhoso e o fantástico". Revista Fronteiraz 3(3). Setembro. PUC-SP. In http://www4.pucsp.br/revistafronteiraz/ numeros_anteriores/n3/download/pdf/revista_fronteiraz_impressao3.pdf Acesso em 15.Mar.2017.

MICHELI, Regina (s/d). Os contos de fadas e o maravilhoso na Literatura Infantojuvenil. RJ: UERJ - PPT.

PROPP, Vladimir (1984). Morfologia do conto maravilhoso. Rio de Janeiro: Forense.

RAMOS, Ana Margarida (2016). Tendências contemporâneas da literatura portuguesa para a infância e a juventude: desafios atuais. Tropelias e Companhia. SARAMAGO, José; BORGES, J. (2016). O Lagarto. São Paulo: Cia das LetrinhasFundação J.Saramago.

TODOROV, Tzvetan (1977). Introdução à Literatura Fantástica. São Paulo: Editora Moraes, 1977. (1970). As estruturas narrativas. São Paulo: Perspectiva. 